\title{
Multi-Zone Drying Schemes for Lowering the Residual Solvent Content during Multi-Component Drying of Semicrystalline Polymers
}

\section{Sim-Siong Wong, Sacide Alsoy Altinkaya \& Surya K. Mallapragada}

To cite this article: Sim-Siong Wong, Sacide Alsoy Altinkaya \& Surya K. Mallapragada (2007) Multi-Zone Drying Schemes for Lowering the Residual Solvent Content during MultiComponent Drying of Semicrystalline Polymers, Drying Technology, 25:6, 985-992, DOI: 10.1080/07373930701396741

To link to this article: http://dx.doi.org/10.1080/07373930701396741

曲 Published online: 16 Jun 2010.

Submit your article to this journal \ulcorner

Џ Article views: 61

View related articles $₫$

Citing articles: 5 View citing articles $\sqsubset$ 


\title{
Multi-Zone Drying Schemes for Lowering the Residual Solvent Content during Multi-Component Drying of Semicrystalline Polymers
}

\author{
Sim-Siong Wong, ${ }^{1}$ Sacide Alsoy Altinkaya, ${ }^{2}$ and Surya K. Mallapragada ${ }^{1}$ \\ ${ }^{1}$ Department of Chemical and Biological Engineering, Iowa State University, Ames, Iowa, USA \\ ${ }^{2}$ Department of Chemical Engineering, Izmir Institute of Technology, Gulbahce Koyu, Urla-Izmir, \\ Turkey
}

\begin{abstract}
The development of a glassy skin in multicomponent semicrystalline polymer systems limits the diffusion of solvents out of the system and increases residual solvent levels. Based on the results of a mathematical model that we had previously developed, we have proposed a multi-zone drying scheme aimed at lowering the residual solvent levels by taking into account the effect of interactions between the various solvents as predicted by the model. This article focuses on the application of this model to develop optimal drying schemes and to verify the effectiveness of these predictions using experimental techniques. The mathematical model developed previously to study the diffusion of multiple solvents and changes in the crystallinity of semicrystalline polymer systems during drying incorporates many features including Vrentas-Duda diffusion theory, solvent-induced crystallization kinetics, as well as glass transition effects and skinning of the film. The multi-zone drying system was developed by varying the drying temperature in each zone as well as changing the partial pressure of individual solvents during the drying process. The effectiveness of the multizone drying schemes predicted by the model was validated experimentally using thermogravimetric methods. The polymer-solvent system chosen was a poly(vinyl alcohol)-water-methanol system. Our experimental data suggested that the multi-zone drying schemes were superior to a single-zone drying system through direct comparison. Further examination of the mathematical model yielded individual solvent profiles and these data reaffirmed our conclusions that a multi-zone drying scheme has the ability to reduce the effect of solvent trapping and thus lower the overall residual solvent content.
\end{abstract}

Keywords Crystallization; Drying; Modeling; Semicrystalline polymers; Thermogravimetric analysis (TGA)

\section{INTRODUCTION}

A good understanding of solvent diffusion and crystallization processes is important in the proper design of dry-

Correspondence: Surya K. Mallapragada, Department of Chemical and Biological Engineering, Iowa State University, 2114 Sweeney Hall, Ames, Iowa 50011-2230; E-mail: suryakm@ iastate.edu ing processes for semicrystalline polymers. Although the drying process of semicrystalline polymer systems with single solvents has been investigated extensively, ${ }^{[1-3]}$ the knowledge of drying processes of semicrystalline polymer systems involving multiple solvents is still scarce. As the polymer films undergo a drying process, their structure and properties change, and careful monitoring is needed to ensure that the quality of the product meets the required specification. Polymer microstructure, mechanical properties, defect formation, and residual solvent content are some of the important factors that need to be considered when designing a proper drying system..$^{[4,5]}$

The growth of crystalline structures within the polymer poses a significant challenge that previous models of solvent removal from amorphous polymers ${ }^{[6-14]}$ cannot fully describe. The formation of crystalline structures hinders the movement of solvents within the polymer, while the transport of solvents has a direct effect on the rate of crystal formation. This interdependence of crystallization and solvent transport is an important feature that needs to be studied extensively. Another potential problem during drying processes is the formation of a glassy skin. Glassy skin formation occurs when the solvents are removed from the system and the local glass transition temperature of the system drops below the drying temperature. Glassy skin formation could further hinder the removal of solvents and may cause solvent trapping. We have developed mathematical models to describe these behaviors, ${ }^{[15,16]}$ and this article focuses on application of these models to develop optimal drying schemes and verification of these theoretical results using experimental techniques.

The amount of harmful solvent residues is exceptionally important for consumer products and food packaging, ${ }^{[17-19]}$ and the optimization of the drying process to achieve minimum residual solvent receives top priority. The mathematical models that we have previously developed integrate 
Vrentas-Duda free volume theory ${ }^{[20,21]}$ with crystallization kinetics and glassy skin formation to paint a detailed picture of the concentration of multiple solvents and the development of crystallites within polymer films. ${ }^{[15,16]}$ From our previous simulation results involving multiple solvent systems, the residual solvent trapped in the film may be higher than acceptable and desirable levels depending on drying conditions. We found that the interaction of the solvents within the film plays an important role in determining the rate of diffusion of individual solvents and the residual solvent content. In our test system, poly(vinyl alcohol) (PVA)-water-methanol system, we found from model predictions that methanol was trapped in the rubbery zone as drying continued, and the solventsolvent interactions are the key factor. The trapping of methanol at the rubbery region increased the overall residual solvent content in the system and may have an effect on the overall properties of the end product. Our simulation results indicated that the presence of water within the film helps the diffusion of methanol, ${ }^{[15,16]}$ and this is due to an increase in free volume within the film by water. In addition, the presence of water lowers the rate of glassy skin formation and growth, thus allowing more methanol to be removed before it is trapped.

Cairncross et al. ${ }^{[8]}$ and Alsoy ${ }^{[22]}$ have analyzed the drying behavior of amorphous polymer-solvents coatings in multiple zone ovens and they have demonstrated that multi-zone ovens can be used to reduce the residual solvent content by controlling the vapor-phase composition, air temperature, and air velocity in each zone. Additionally, these studies have shown that by varying the operating conditions at the entrance of each zone, bubble formation due to solvent boiling can be eliminated without lowering the process speed. Based on the findings from these studies, we have proposed a multi-zone drying scheme that will take advantage of the interactions between diffusion of water and methanol. We have chosen to study the effect of drying temperature and partial pressure of solvents as they are expected to have the most profound effect. In our case, a two-zone drying scheme was set up with a low-temperature zone followed by a high-temperature zone. The purpose of the lower temperature zone is to reduce the difference in the diffusion rate of water and methanol to promote the removal of methanol. The higher temperature zone that follows will drive out the remaining residual solvent to achieve minimum solvent levels. The control of partial pressure of solvent was achieved by introducing humidity during the drying process. The role of increasing the partial pressure of one solvent in the drying process would be to provide selectivity of removal of the other solvent in a multi-component system. By lowering the mass transfer driving force of a particular solvent, the rate of solvent removal of an individual solvent can be adjusted selectively.

\section{EXPERIMENTAL}

\section{Materials}

Poly(vinyl alcohol) (PVA) powders with molecular weight 133,000 (Polysciences, Warrington, PA) were used without further purification. The PVA used was fully hydrolyzed (degree of hydrolysis $>99.0 \%$ ) with a polydispersity index of 2.15 . The PVA solution $(10 \% \mathrm{w} / \mathrm{v})$ was prepared by dissolving the PVA powder in water-methanol mixture at $75^{\circ} \mathrm{C}$ for $6 \mathrm{~h}$. The composition of the water-methanol mixture varies from 1:1 water:methanol volume ratio to $4: 1$ water:methanol volume ratio. The PVA solutions were kept at $40^{\circ} \mathrm{C}$ until they were used in drying experiments.

\section{Degree of Crystallinity}

The final degree of crystallinity of the polymer was determined using differential scanning calorimetry (DSC; DSC7, Perkin-Elmer, Boston, MA). A small sample of polymer of known weight was heated from 25 to $250^{\circ} \mathrm{C}$ at $10^{\circ} \mathrm{C} / \mathrm{min}$ to determine its melting profile. The $\Delta H_{\text {melt }}$ measured using this technique was compared to the $\Delta H_{\text {melt }}$ of pure PVA crystals from literature $(138.6 \mathrm{~J} / \mathrm{g}){ }^{[23]}$ The data were used in the mathematical model and are listed in Table 1.

\section{Drying Kinetics}

The drying experiments were performed using thermogravimetric analysis (TGA; TGA7, Perkin-Elmer, Boston, MA) to monitor the weight of the sample and control the temperature of the environment as drying occurred. A 40-mg sample from the stock solution was used in each of the experiments. A consistent $30 \mathrm{~mL} / \mathrm{min}$ top-side air flow was used throughout the experiment.

Three different drying conditions were designed to investigate the effectiveness of the multi-zone drying scheme. The first set of experiments involved single-zone drying at a drying temperature of $75^{\circ} \mathrm{C}$ for $3 \mathrm{~h}$ (Case 1). The second set of experiments involved two zones with drying temperatures of $25^{\circ} \mathrm{C}$ for $1 \mathrm{~h}$ followed by $75^{\circ} \mathrm{C}$ for an additional $2 \mathrm{~h}$ (Case 2). The third set of experiments was similar to the second set with one modification: during the first zone $\left(25^{\circ} \mathrm{C}\right)$, humidity was introduced through the incoming air, and dried air was used when the temperature was raised to $75^{\circ} \mathrm{C}$ (Case 3). Humidity was introduced by bubbling the incoming air through a gas bubbler filled with water to increase the partial pressure of water in the drying environment. These drying schemes were established based on our knowledge of the effect of temperature and partial pressure of solvents on the residual solvent, as well as the connection between the rates of diffusion of water and methanol. 
TABLE 1

Properties of the polymer system ${ }^{[24,25]}$

\begin{tabular}{ll}
\hline System properties & \\
\hline Heat capacity, $\widehat{C}_{p}^{p}$ & $1.674 \mathrm{~J} \mathrm{~g}^{-1} \mathrm{~K}^{-1}$ \\
Density of polymer, $\rho^{p}$ & $1.294 \mathrm{~g} \mathrm{~cm}^{-3}$ \\
Heat of vaporization of water, $\Delta \widehat{H}_{1}$ & $2404 \mathrm{~J} \mathrm{~g}^{-1}$ \\
Heat of vaporization of methanol, $\Delta \widehat{H}_{2}$ & $1155 \mathrm{~J} \mathrm{~g}^{-1}$ \\
Final degree of crystallinity of the polymer & 0.3558 \\
Initial and operating conditions & \\
Initial temperature, $T_{0}$ & $298 \mathrm{~K}$ \\
Initial thickness, $L_{0}$ & $1 \mathrm{~mm}$ \\
Initial volume fraction of the polymer & 0.1 \\
Heat transfer coefficient, $h$ & $0.029 \mathrm{~W} \mathrm{~cm}^{-2} \mathrm{~K}^{-1}$ \\
Solvent 1 mass transfer coefficient, $k_{1}{ }^{m}$ & $2.07 \times 10^{-10} \mathrm{~s} \mathrm{~cm}^{-1}$ \\
Solvent 2 mass transfer coefficient, $k_{2}{ }^{m}$ & $1.67 \times 10^{-14} \mathrm{~s} \mathrm{~cm}^{-1}$ \\
Mole fraction of solvent 2 in gas & 0 \\
\hline
\end{tabular}

\section{MATHEMATICAL MODELING}

The mathematical model previously developed takes into account multicomponent diffusion of the solvents as well as solvent-induced crystallization. Figure 1 shows a schematic of the development of glassy skin and crystal formation as solvents were removed from the system. A polymer solution involving two solvents, with thickness $L_{0}$, was deposited on a substrate and subjected to various drying conditions. As solvents are removed from the system, the thickness of the film, $L$, decreases while a layer of glassy skin, $R$, was developed and created a glassy region on top of the rubbery region. In the rubbery region, crystals are formed due to solvent-induced crystallization. A detailed description of the model and its governing equations can be found elsewhere. ${ }^{[16]}$ Only the salient features of the model are presented below.

An integrated model with Vrentas-Duda free volume theory and crystal formation mechanism is used to predict the solvent concentration in both glassy and rubbery regions. For the rubbery region, species continuity

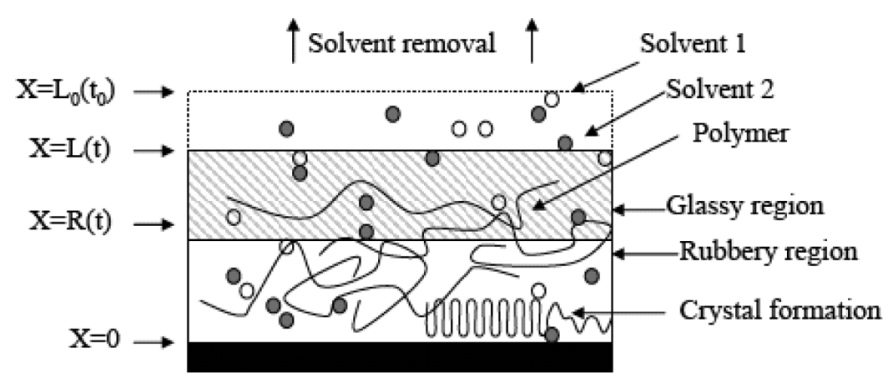

FIG. 1. The illustration of drying of semicrystalline polymers. equation is as follows:

$$
\frac{\partial w_{i}}{\partial t}+\frac{\partial}{\partial x}\left(w_{i} v^{\neq}\right)=\frac{\partial}{\partial x}\left(\sum_{j=1}^{N-2} D_{i j}^{R} \frac{\widehat{V}_{i}}{\widehat{V}_{j}} \frac{\partial w_{j}}{\partial x}\right)
$$

In this equation, $w_{i}$ represents the volume fraction of the individual component $i, v^{\neq}$is the volume average velocity due to the convective effect generated by crystallization, $\widehat{V}_{i}$ is the partial specific volume, and $D_{i i}$ and $\mathrm{D}_{i j}$ represent the main and cross diffusion coefficients, respectively.

$$
\begin{gathered}
\frac{\partial v}{\partial t}=r_{c} \widehat{V}_{4} \\
r_{c}=-k \frac{v}{\widehat{V}_{4}}\left(v-v_{\infty}\right) \\
k=k_{0} \exp -\left(\frac{\left(\omega_{1} \widehat{V}_{1}^{*} / \xi_{13}^{R}\right)+\left(\omega_{2} \widehat{V}_{2}^{*} / \xi_{23}^{R}\right)+\omega_{3} \widehat{V}_{3}^{*}}{\widehat{V}_{F H} / \gamma}\right)
\end{gathered}
$$

Equations (2) to (4) describe the crystallization process. The rate of crystallization $r_{c}$ is a function of the rate constant, $k$, and the current and final volume fraction of crystalline polymer $\left(v, v_{\infty}\right) \cdot v_{\infty}$ is calculated based on the degree of crystallinity described in earlier section. The rate constant takes into account the individual weight fractions as well as its free volume contribution. For the glassy region, a similar equation can be written:

$$
\frac{\partial w_{i}}{\partial t}=\frac{\partial}{\partial x}\left(\sum_{j=1}^{N-2} D_{i j}^{G} \frac{\widehat{V}_{i}}{\widehat{V}_{j}} \frac{\partial w_{j}}{\partial x}\right)
$$

Since no crystallization takes place in this region, the convective term is dropped. For a two-region system, three boundary conditions are needed to complete the model. 
First, at the polymer-substrate boundary, we assume that no mass transfer takes place. For the glassy-rubbery interface, mass flux of the individual components is written as:

$$
\begin{aligned}
- & \frac{D_{i 1}^{R}}{\widehat{V}_{1}} \frac{\partial w_{1}}{\partial x}-\frac{D_{i 2}^{R}}{\widehat{V}_{2}} \frac{\partial w_{2}}{\partial x}-\frac{w_{i}}{\widehat{V}_{i}} \frac{d R}{d t}+\frac{w_{i}}{\widehat{V}_{i}} v^{\neq} \\
= & -\frac{D_{i 1}^{G}}{\widehat{V}_{1}} \frac{\partial w_{1}}{\partial x}-\frac{D_{i 2}^{G}}{\widehat{V}_{2}} \frac{\partial w_{2}}{\partial x}
\end{aligned}
$$

Lastly, at the polymer-air interface, the mass flux at the interface is described as:

$$
-\frac{D_{i 1}^{G}}{\widehat{V}_{1}} \frac{\partial w_{1}^{a}}{\partial x}-\frac{D_{i 2}^{G}}{\widehat{V}_{2}} \frac{\partial w_{2}^{a}}{\partial x}-\frac{w_{i}}{\widehat{V}_{i}} \frac{d L}{d t}=k_{i}^{m}\left(P_{i}^{i}-P_{i}^{b}\right)
$$

As the polymer films are very thin, a single overall temperature profile is used. The temperature of the system takes into account the heat transfer properties of the system with its surrounding environment, the heat loss due to evaporation of solvents, as well as required heat of crystallization for the semicrystalline polymer to develop. A detailed description of the model and the parameters of the PVA-water-methanol system can be found elsewhere. ${ }^{[16]}$

To vary the operating conditions within the model, smoothed Heaviside function with continuous first derivative without overshoot was used to avoid problems associated with discontinuity of variables. The initial and operating conditions of the model mimic the initial and operating conditions of the experiments described previously. This allows comparison of the experimental data and simulation results as well as provides additional information that was not available through experimental means regarding the drying scheme. MATLAB ${ }^{\circledR}$ (MathWorks, Natick, MA) and COMSOL Multiphysics ${ }^{\circledR}$ (Comsol, Burlington, MA) software were used to solve the model equations.

\section{RESULTS AND DISCUSSION}

To study the effectiveness of the multi-zone drying scheme, the overall residual solvent content in the two-zone drying scheme was compared with a single-zone drying scheme, and the results are shown in Figs. 2-4. Figures 2a-2c compare the effectiveness of Case 2 to Case 1. The $y$-axis was plotted on the log scale to better showcase the differences between the different drying schemes. In Figs. $2 \mathrm{a}-2 \mathrm{c}$, the performance of the two-zone drying scheme began to overtake the single-zone drying scheme after about 100-120 min and continued to improve after $3 \mathrm{~h}$ of drying. On average, the two-zone drying scheme achieved $30 \%$ improvement in overall residual solvent level over the single-zone drying scheme. In Figs. 3a-3c, we observed the same behavior where the two-zone drying scheme (Case 3) outperformed the single-zone drying scheme after about
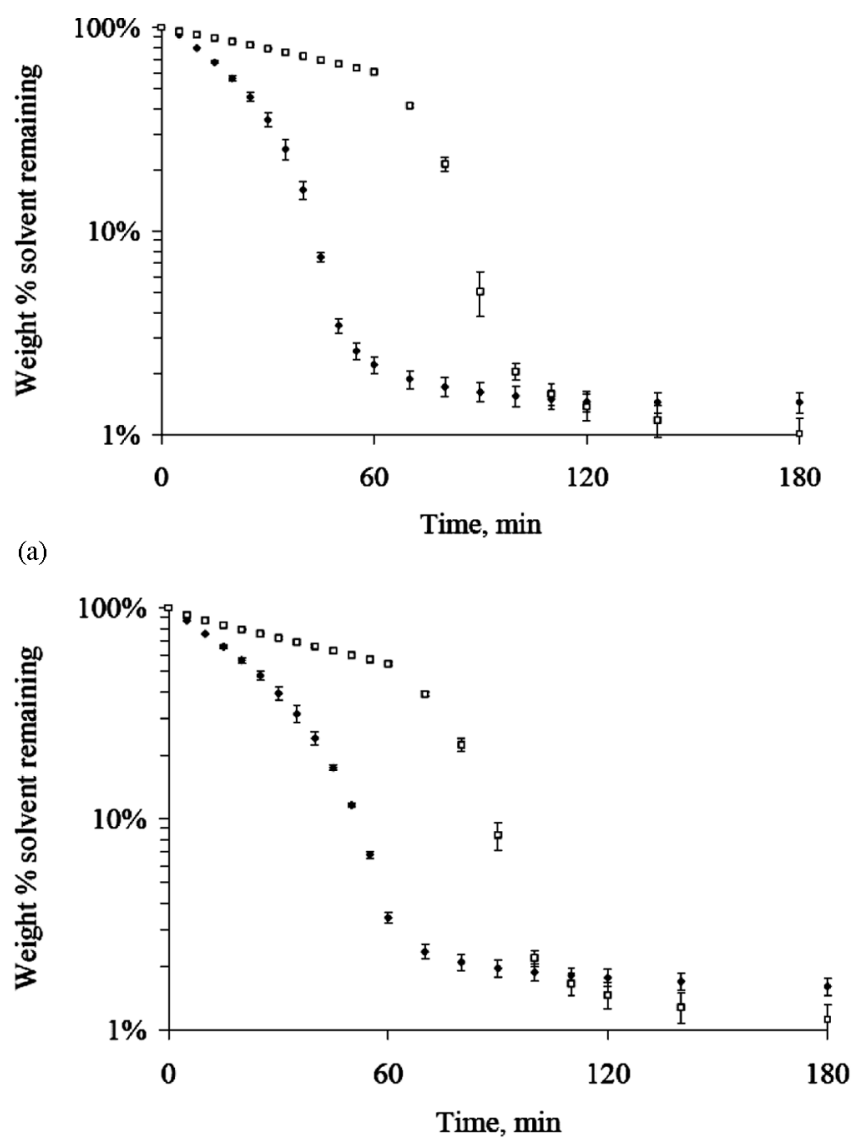

(b)

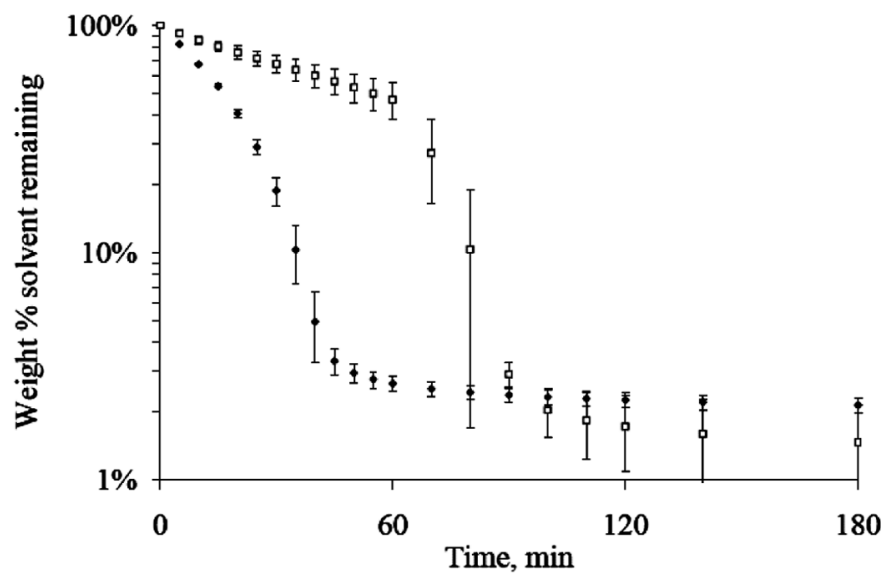

(c)

FIG. 2. Comparison of the overall residual solvent content (weight\%) for Case $1\left(75^{\circ} \mathrm{C}\right)$ and Case $2\left(25^{\circ} \mathrm{C} / 75^{\circ} \mathrm{C}\right)$ for (a) 4:1 water:methanol ratio, (b) 2:1 water:methanol ratio, and (c) 1:1 water:methanol ratio. ( $\bullet$ ) Represents residual solvent for Case 1, while ( $\square$ ) represents solvent residue for Case 2.

$2 \mathrm{~h}$ drying time. After $3 \mathrm{~h}$, the two-zone drying scheme surpassed the single-zone drying scheme by an average of $32 \%$ in overall residual solvent level. Figure 4 shows the 


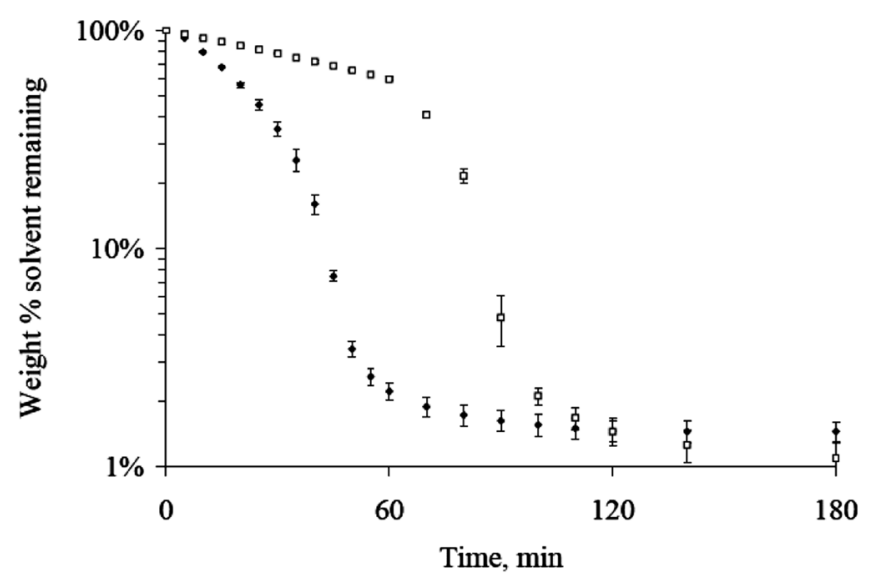

(a)

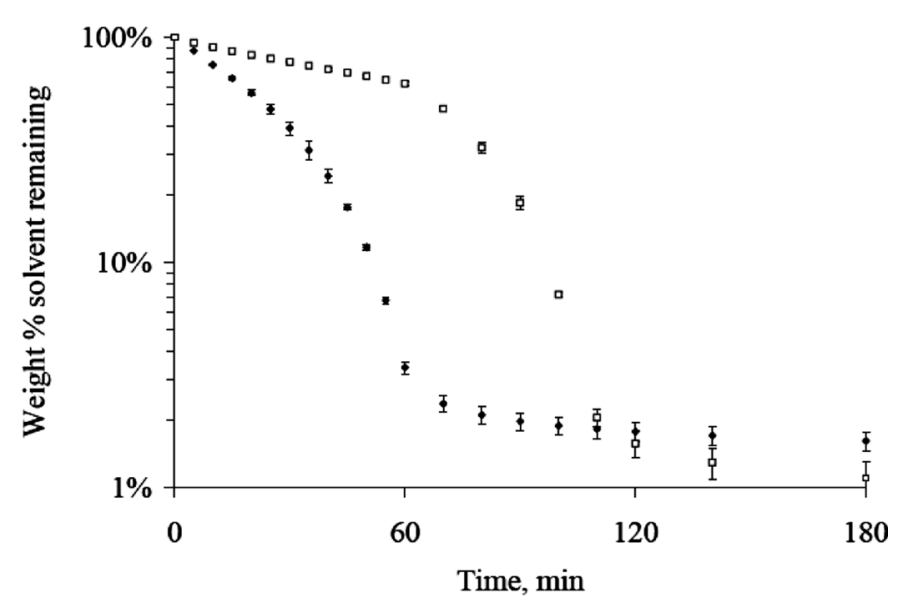

(b)

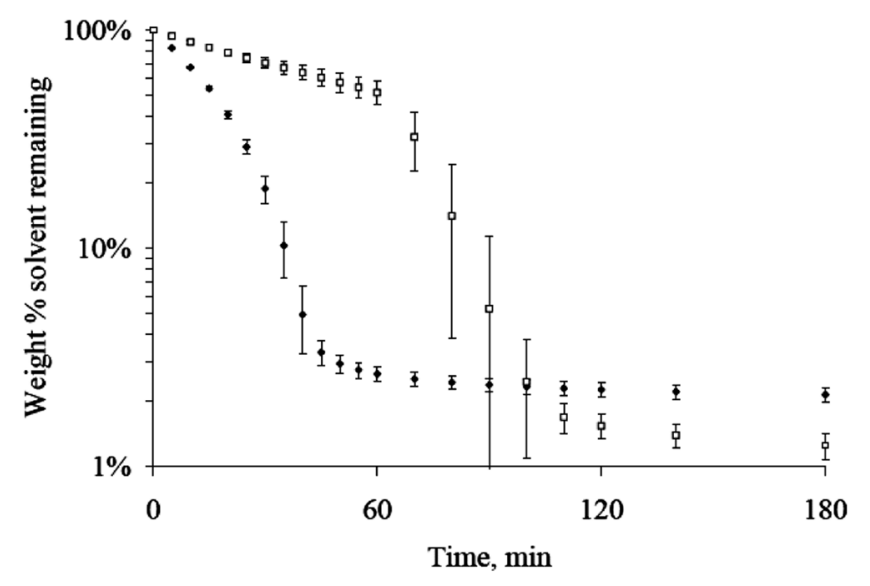

(c)

FIG. 3. Comparison of the overall residual solvent content (weight \%) for case $1\left(75^{\circ} \mathrm{C}\right)$ and case $3\left(25^{\circ} \mathrm{C}\right.$ humidity $\left./ 75^{\circ} \mathrm{C}\right)$ for (a) $4: 1$ water:methanol ratio, (b) 2:1 water:methanol ratio, and (c) 1:1 water:methanol ratio. $(\diamond)$ Represents residual solvent for case 1 , while $(\square)$ represents solvent residue for case 3 .

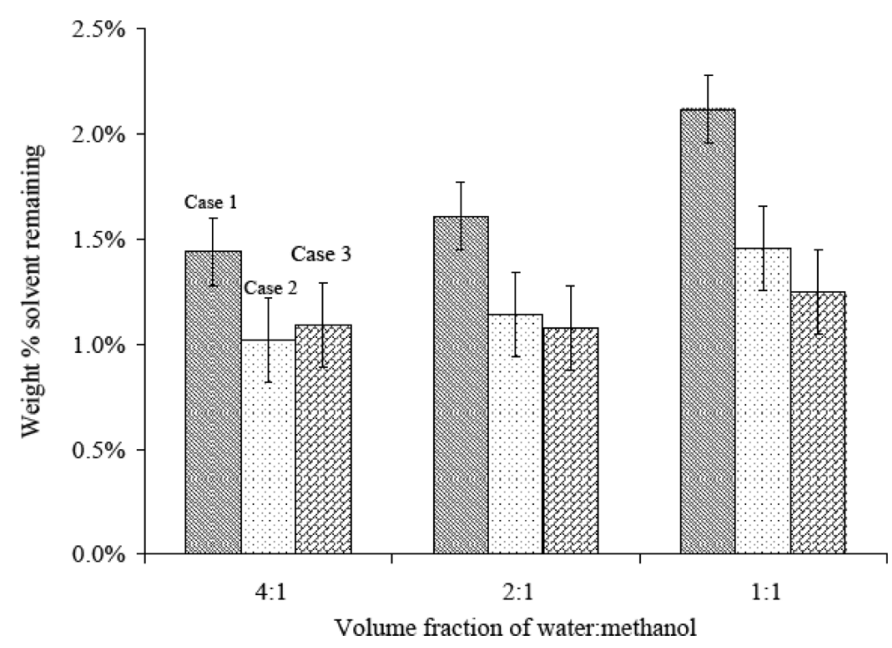

FIG. 4. Summaries of the final overall residual solvent content for the different cases.

comparison of final residual solvent for each case with different initial solvent compositions. From the figures, we find that as the composition of methanol in the film increased, the final overall residual solvent increased. This was another indication that methanol trapping was likely the cause of high residual solvent in the film. After comparing the results obtained in Cases 2 and 3, the humidity effect was not found to have a significant influence when there was a high composition of water present in the film. This suggests that the positive effect of water on methanol removal has a limiting effect. For the $4: 1$ water:methanol initial ratio, the additional humidity did not improve the overall residual solvent. As the initial composition of methanol increased, a 5 and $14 \%$ improvement in residual solvent level between Cases 2 and 3 was observed in the final dried film.

To bridge the information obtained from experiments and the insights that the mathematical model provides, the exact operating conditions of the experiments were inserted into the mathematical model. Table 1 lists the common initial and operating conditions as well as the properties of the polymer system. Based on the parameters listed, the simulations were performed for various initial and operating conditions discussed previously and the results were compared with the experimental data as shown in Fig. 5. Figures $5 \mathrm{a}-5 \mathrm{c}$ show the comparison of experimental data and simulation predictions for the 4:1 water:methanol ratio for each case. Overall, the simulation results matched well with the experimental data obtained. The simulation results for other compositions showed similar good agreement with the experimental data obtained. This allowed further examination of the mathematical model to extract additional information that was not available through experimental methods: the composition of individual solvent. Figures 6 and 7 show the volume 


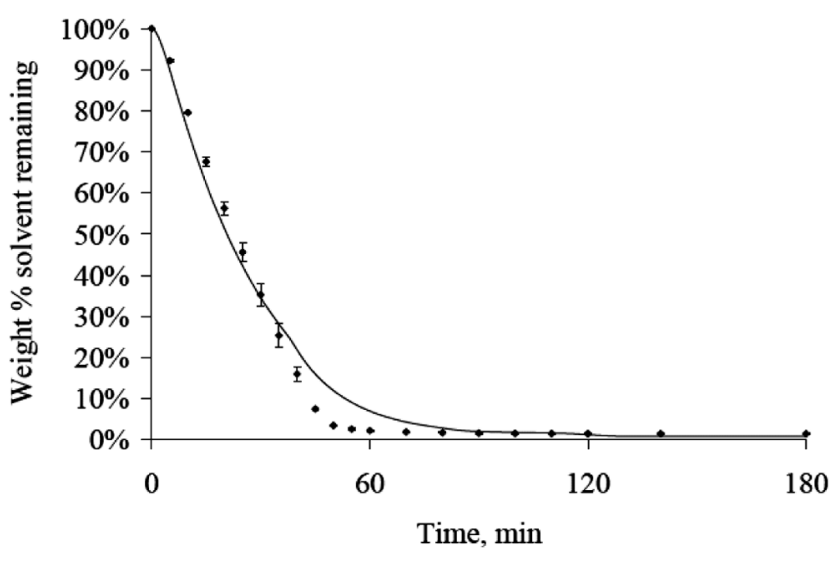

(a)

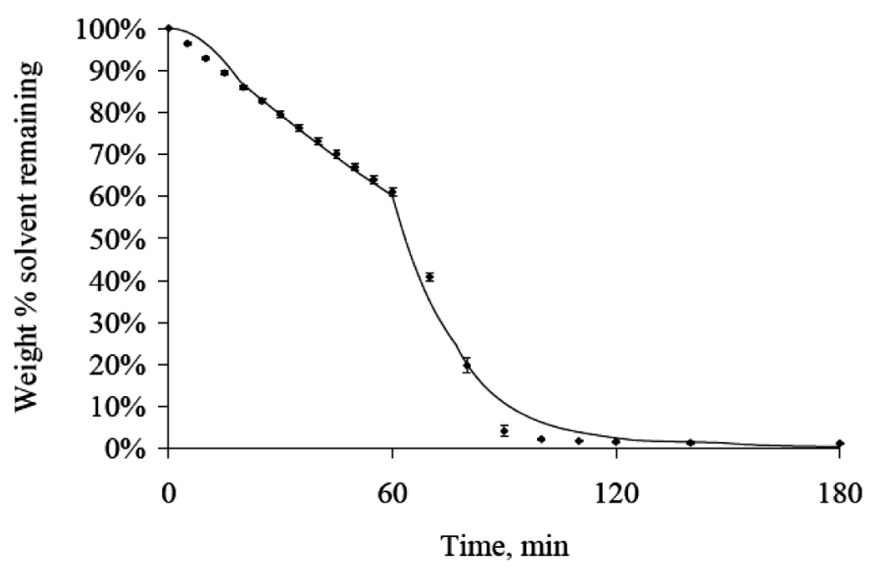

(b)

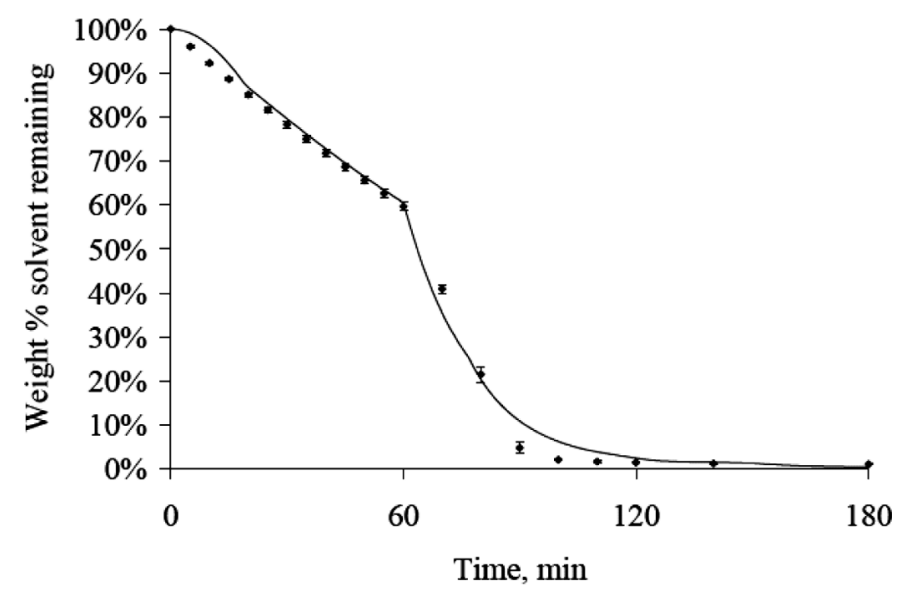

(c)

FIG. 5. Comparison of overall residual solvent content based on simulation results and experimental data for (a) Case $1\left(75^{\circ} \mathrm{C}\right)$, (b) Case 2 $\left(25^{\circ} \mathrm{C} / 75^{\circ} \mathrm{C}\right)$, and (c) Case $3\left(25^{\circ} \mathrm{C}\right.$ humidity $\left./ 75^{\circ} \mathrm{C}\right)$. ( $)$ Represents residual solvent level obtained from experimental data, while $(-)$ represents residual solvent levels obtained from simulation results.

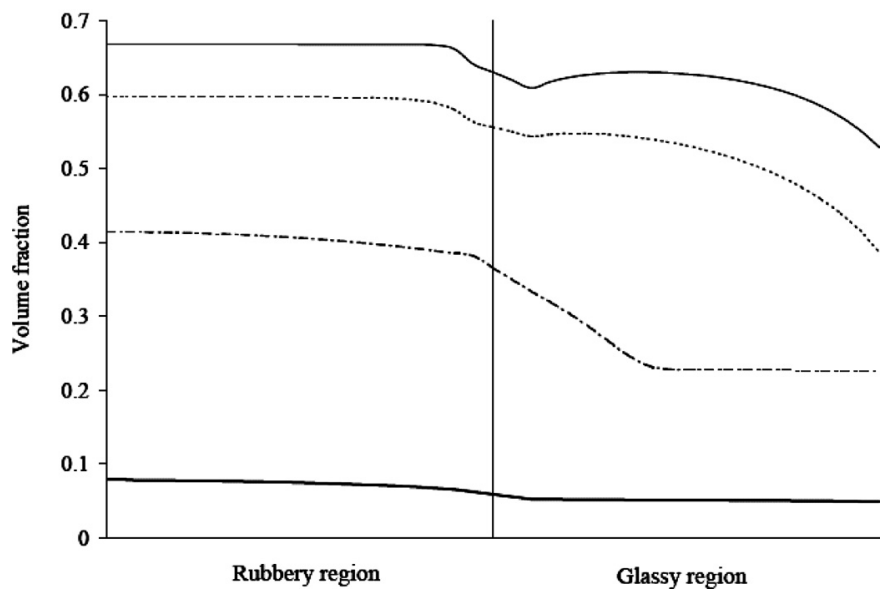

FIG. 6. Volume fraction of water in rubbery and glassy regions during drying $\left(75^{\circ} \mathrm{C}\right),(-)$ represents the volume fraction profile at $10 \mathrm{~min}$ into drying. $(\cdots),(-\cdot)$, and (-) represent the volume fraction profiles at 30 , 60 , and $90 \mathrm{~min}$ into drying, respectively.

fraction of water and methanol across the film during drying, respectively. Figure 7 shows that the methanol composition in the rubbery zone is much higher than the glassy zone, which is an indication of methanol trapping. The results from these local compositions were integrated to obtain the individual residual solvent level and Figure 8 shows the final composition of methanol and water for each case and initial composition. There is a clear improvement in the methanol residual content in the two-zone drying scheme compared with the single-zone drying scheme regardless of the initial composition of methanol. This agreed well with our experimental data that showed that a two-zone drying scheme was more effective in removal of solvents, and solvent trapping can be reduced using such a scheme. Overall, as the initial composition of methanol increased, the final residual solvent content increased. This was consistent with the experimental data obtained. Figure 8 shows that the residual content of water increased as the initial composition of methanol increased, and it is possibly due to interaction of the two solvents in the PVA films. The addition of humidity into the drying scheme has a positive effect in removing methanol. As the humidity level in the air is increased, the driving force for the evaporation of water from the surface decreases causing a negative effect on the rate of removal of water from the solution. It can be seen from Fig. 8 that this situation was observed when the water methanol ratios were $4: 1$ and 2:1 respectively. At the lowest water methanol ratio of 1:1, the model predicts lower residual water content when the solution is dried in a humid atmosphere. This can be explained by the dominant effect of internal resistance on the overall rate of drying. With increased methanol concentrations, free volume of the system increases, which increases the rate of diffusion of both 


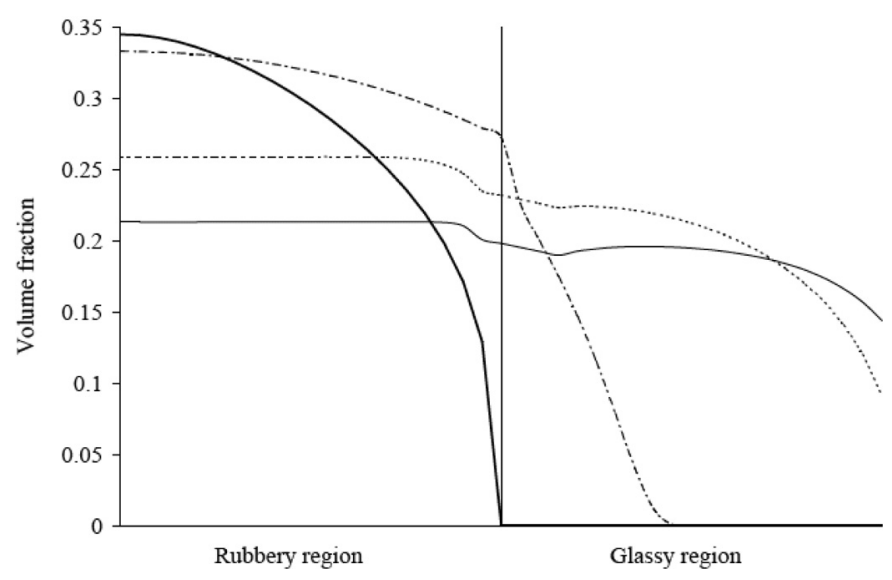

FIG. 7. Volume fraction of methanol in rubbery and glassy regions during drying $\left(75^{\circ} \mathrm{C}\right),(-)$ represents the volume fraction profile at $10 \mathrm{~min}$ into drying. $(\cdots),(-\cdot)$, and $(-)$ represent the volume fraction profiles at 30,60 , and 90 min into drying, respectively.

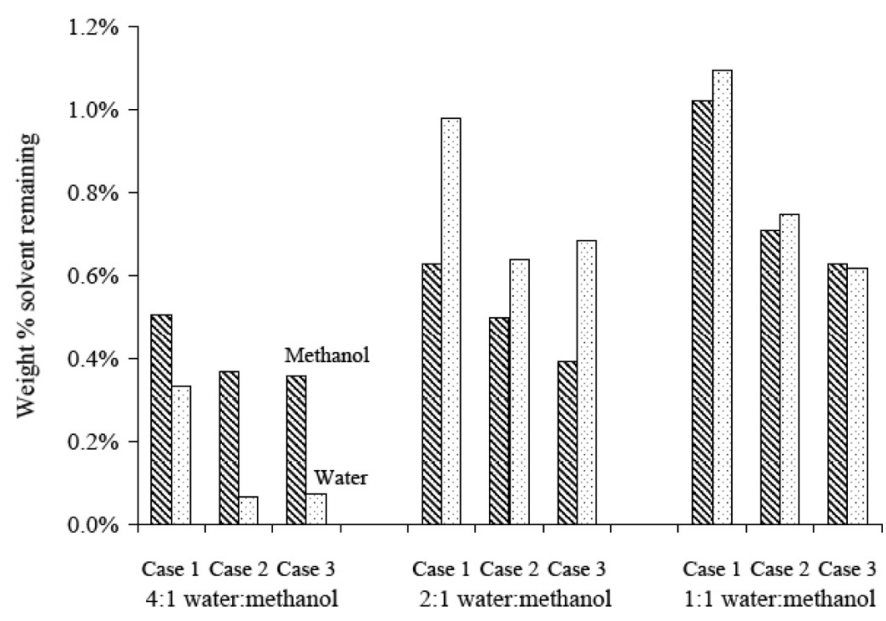

FIG. 8. Final residual solvent content for individual solvents obtained from simulation results.

solvents. Consequently, the decrease in driving force for the evaporation of water due to an increase in relative humidity of air is compensated by its enhanced diffusion rate in the dried solution.

\section{CONCLUSIONS}

Skin formation during the drying of semicrystalline polymer solution is a result of combined effects of crystal formation, glassy-rubbery transition, and the differences in the volatility and diffusivity of solvents in the dried solution. Based on the results of a previously developed mathematical model, we have proposed a multi-zone drying scheme and examined the efficacy of such a scheme compared with the single-zone drying scheme in reducing residual solvent content in a multicomponent semicrystalline polymer system. We found that the multi-zone drying scheme was superior in reducing the overall residual solvent of the film. Through the mathematical model, we were able to replicate the experimental conditions and found that the results from both match well. Furthermore, we were able to obtain the contents of individual solvents within the film using the model and examine the overall total solvent level during the course of drying. The use of the mathematical model provides information that is not readily available through experimental means and this will help to better understand the interactions between solvents and polymers during the drying process. There are many approaches toward improving drying operations, and this model can be used as a tool to design a better drying system.

\section{ACKNOWLEDGEMENTS}

The authors thank the National Science Foundation for financial support through NSF-CTS0107168.

\section{REFERENCES}

1. Ngui, M.O.; Mallapragada, S.K. Mechanistic investigation of drying regimes during solvent removal from poly(vinyl alcohol) films. Journal of Applied Polymer Science 1999, 72, 1913-1920.

2. Ngui, M.O.; Mallapragada, S.K. Understanding isothermal semicrystalline polymer drying: Mathematical models and experimental characterization. Journal of Polymer Science, Part B: Polymer Physics 1998, 36, 2771-2780.

3. Ngui, M.O.; Mallapragada, S.K. Quantitative analysis of crystallization and skin formation during isothermal solvent removal from semicrystalline polymers. Polymer 1999, 40, 5393-5400.

4. Price, P.E., Jr.; Cairncross, R.A. Optimization of single-zone drying of polymer solution coatings using mathematical modeling. Journal of Applied Polymer Science 2000, 78, 149-165.

5. Price, P.E., Jr.; Cairncross, R.A. Optimization of single-zone drying of polymer solution coatings to avoid blister defects. Drying Technology 1999, 17, 1303-1311.

6. Errede, L.A.; Kueker, M.J.; Tiers, G.V.D.; Van Bogart, J.W.C. Polymer drying, 1. Time-studies of desorption from liquid saturated poly(styrene-co-divinylbenzene) microparticles. Journal of Polymer Science, Part A: Polymer Chemistry 1988, 26, 3375-3389.

7. Vrentas, J.S.; Vrentas, C.M. Surface concentration effects in the drying of solvent-coated polymer films. Journal of Applied Polymer Science 1996, 60, 1049-1055.

8. Cairncross, R.A.; Durning, C.J. A model for drying of viscoelastic polymer coatings. AIChE Journal 1996, 42, 2415-2425.

9. Cairncross, R.A.; Jeyadev, S.; Dunham, R.F.; Evans, K.; Francis, L.F.; Scriven, L.E. Modeling and design of an industrial dryer with convective and radiant heating. Journal of Applied Polymer Science 1995, 58, 1279-1290.

10. Okazaki, M.; Shioda, K.; Masuda, K.; Toei, R. Drying mechanism of coated films of polymer solutions. Journal of Chemical Engineering of Japan 1974, 7, 99-105.

11. Edwards, D.A. An asymptotic analysis of polymer desorption and skinning. Macromolecular Theory and Simulations 1999, 8, 10-14.

12. Alsoy, S.; Duda, J.L. Modeling of multilayer drying of polymer films. Journal of Polymer Science, Part B: Polymer Physics 1999, 37, $1665-1675$. 
13. Alsoy, S.; Duda, J.L. Modeling of multicomponent drying of polymer films. AIChE Journal 1999, 45, 896-905.

14. Alsoy, S.; Duda, J.L. Drying of solvent coated polymer films. Drying Technology 1998, 16, 15-44.

15. Wong, S.-S.; Altinkaya, S.A.; Mallapragada, S.K. Drying of semicrystalline polymers: mathematical modeling and experimenta characterization of poly(vinyl alcohol) films. Polymer 2004, 45, 5151-5161.

16. Wong, S.-S.; Altinkaya, S.A.; Mallapragada, S.K. Understanding the effect of skin formation on the removal of solvents from semicrystalline polymers. Journal of Polymer Science, Part B: Polymer Physics 2005, 43, 3191-3204.

17. Miltz, J.; Passay, N.; Mannheim, C.H. Mass transfer from and through packaging materials. Packaging Technology \& Science 1992, 5, 49-56.

18. Miltz, J.; Rosen-Doody, V. Migration of styrene monomer from polystyrene packaging materials into food simulants. Journal of Food Processing and Preservation 1984, 8, 151-161.
19. Nir, M.M.; Ram, A.; Miltz, J. Sorption and migration of organic liquids in poly(ethylene terephthalate). Polymer Engineering and Science 1996, 36, 862-868.

20. Duda, J.L.; Vrentas, J.S.; Ju, S.T.; Liu, H.T. Prediction of diffusion coefficients for polymer-solvent systems. AIChE Journal 1982, 28, 279-285.

21. Vrentas, J.S.; Duda, J.L. Diffusion in polymer-solvent systems. I. Reexamination of the free-volume theory. Journal of Polymer Science, Polymer Physics Edition 1977, 15, 403-416.

22. Alsoy, S. Predicting drying in multiple-zone ovens. Industrial \& Engineering Chemistry Research 2001, 40, 2995-3001.

23. Peppas, N.A.; Merrill, E.W. Poly(vinyl alcohol) hydrogels: reinforcement of radiation-crosslinked networks by crystallization. Journal of Polymer Science, Polymer Chemistry Edition 1976, 14, 441-457.

24. Brandrup, J.; Immergut, E.H., Eds. Polymer Handbook; John Wiley \& Sons: New York, 1989.

25. Perry, R.H.; Green, D.W.; Maloney, J.O., Eds. Perry's Chemical Engineer's Handbook; McGraw-Hill: New York, 1997. 